\title{
VIEWPOINT
}

\section{What Drives Us to Walk: Understanding Components and Processes of Behaviour Change Towards Active Mobility}

\author{
Alexandra Millonig \\ Digital Resilient Cities, AIT Austrian Institute of Technology, Vienna, AT \\ alexandra.millonig@ait.ac.at
}

\begin{abstract}
Walking is widely promoted as a healthy and sustainable way to get around. Still, although the benefits of walking are undisputed, it is equally known that most people walk much less than they could and should do. This article explores this discrepancy from the angle of human behaviour change processes and applies a theoretically grounded systematics for identifying the most important barriers against walking. This is followed by a description of behaviour types and related behaviour change motives to inspire strategies and arguments to address different types of target groups. The proposed framework can support the selection of measures and strategies to increase walking in different environments and addressing specific social groups.
\end{abstract}

Keywords: walking; behaviour change barriers; motives; mobility; transport planning; motivations for walking

\section{Introduction}

Walking is the most natural type of movement and has also been the primary form of locomotion for almost the entire history of the modern homo sapiens (Kelly, Murphy and Mutrie, 2017). However, starting with the industrial era walking has gradually lost its importance as a means to get around. Nowadays, walking is in most cases just a means to get to and from a motorised mode of transport, and the share of "pure" walking trips is continuously decreasing. Between the last two large national mobility surveys in Austria in 1995 and 2013/2014, for example, the national modal split saw growth in every category of transport modes except walking, while the share of trips on foot dropped by $35 \%$ in this time span (Tomschy R. et al., 2016).

This is happening despite increasing efforts to promote active travelling and a high awareness regarding the benefits of walking in the population. Walking is not just good for individual physical health, as has been demonstrated by the World Health Organization's Health Economic Assessment Tool (HEAT) for walking and for cycling (WHO); there is also evidence that walking may be comparable to psychological or pharmacological treatments for mental health problems such as clinical depression (Robertson et al., 2012).

So, why are the awareness concerning individual gains from walking and the actual decision to walk currently trending increasingly in different directions? To change this trend and to raise the share of walking trips, it is necessary to systematically understand the barriers people experience before deciding whether or not to make a trip by foot.

\section{Physical and mental walking barriers}

There are several different theories offering explanations regarding human behaviour patterns and related influence factors. A theory which provides a comprehensible and simple approach to dissect potential behaviour change barriers in different categories is the sociology-based Social Practice Theory (SPT) (Reckwitz, 2002; Shove, Pantzar and Watson, 2012). According to this theory, three basic components of everyday routines need to be given to perform a specific behaviour: the things that are required to do something (the "material"), the skills and knowledge necessary to use these things (the "competences"), and the reasons why a behaviour is performed (the "meaning"). Transferred to the mobility context, these three components can be relabelled as physical "access", mental "ability" and emotional "ambition" (Millonig, 2019). For the context of walking, "access" would include walkable environments with local destinations and facilities in reach as well as physical fitness or barrier-free walking infrastructure, "ability" would include, for example, navigation skills or experience with information systems to plan a walking route and "ambition" would concern the motivation to walk and the personal gain an individual associates with walking. This distinction of components enabling a person to choose walking as the best transport mode for a trip allows a systematic consideration of potential barriers which might hinder a person to walk. Table $\mathbf{1}$ exemplifies several barriers and their potential impact on the decision to walk. 
Table 1: Potential barriers affecting access, ability and ambition of walking.

\begin{tabular}{lll}
\multicolumn{1}{c}{ Potential barriers } & Impact on decision to walk \\
\hline \multirow{2}{*}{ ACCESS } & Socio-economic barriers: & Living in safe and walkable environments \\
& Limited financial means & not affordable \\
& Information barriers: & Restricted to routes with enough infor- \\
& Insufficient data concerning walking environment or reachable infra- & mation or experience available
\end{tabular}
structure (e.g. benches, facilities)

Physical/sensory health barriers:

Limited physical and motoric functions (agility, physical strength, fatigue, walking impediment), limited sensory perception (vision, hearing)

\section{ABILITY Cognitive health barriers:}

Limited cognitive functions (attention, response time, working memory, dementia)

\section{Usability barriers:}

Lack of experiences/training with new/unfamiliar information sources (e.g. walkability maps, smartphone apps)

\section{AMBITION Social norm related barriers:}

Definition of acceptable and desirable behaviour (related to age/social group/milieu/gender)

\section{Personal experience barriers:}

Reduced self-efficacy and motivation (depression, fear, lack of enjoyment, convenience, time constraints, etc.)
Restricted to barrier free walking infra-

structure and information

Restricted to familiar routes, avoidance of new or complex trips

Restricted to familiar routes and information sources

Avoidance of non-compliant behaviour (walking routes, times of travel)

Avoidance of uncomfortable/ frightening situations or basic lack of desire to walk

Besides providing a comprehensive structure to assess walking barriers, this approach also gives a rough indication of which socio-economic group characteristics might be most affected by specific barriers. Many of the barriers related to access and ability affect older people, while ambition barriers are more frequently experienced by younger generations where walking is either unpopular or difficult to realise due to distance and time constraints. Within the latter group it is especially females who may avoid walking out of subjective fear in unfamiliar or dark, secluded environments. Hence, characteristics like age, gender and financial situation may hinder walking even if it is desired in principle, which results in social inequalities regarding the potential to walk, whereas emotional barriers rooted in convenience or other affective motives (Johansson, Sternudd and Kärrholm, 2016) can affect anyone and demand more than the removal of obstacles against a desired behaviour, but need to address the lack of motivation itself.

\section{Walking drivers and behaviour change strategies}

This form of barrier analysis can provide a useful initial basis for developing measures to reduce walking barriers; however, ambition barriers deserve an additional step of exploration as they are strongly influenced by group-specific preferences and aversions. Several studies have performed target group segmentation approaches on the basis of attitudinal and behavioural patterns related to mobility, which can help understand emotional influences and habits, e.g. Haustein and Hunecke (2013), Prillwitz and Barr (2011) or Krizek and Waddell (2002). Markvica et al. (2020) describe six different types based on the level of willingness of people to change their habits and arguments motivating them (e.g. rationality, sustainability, health, fun) as well as preferred information channels. In an earlier study, Millonig (2014) analysed the spatio-temporal patterns and motives driving the behaviour of pedestrians in shopping environments, also discussing in detail similarities and differences in comparison to typologies of walking motives in previous studies. This or similar typologies can disclose typical motives that can be used to develop strategies to promote walking based on target group specific interests. Table $\mathbf{2}$ juxtaposes assessed spatio-temporal patterns, characteristics and motives of six types of potential walkers based on two studies performed by the author.

The characteristics of attitude-based types can be used to inform motivational strategies which have the potential to spark "intrinsic" motivation for behaviour change. Contrary to "extrinsic" behaviour change motivation as provided, for example, in gamified fitness apps or vouchers for walking, intrinsic motivation frames a target behaviour as desirable in itself, so the "new" behaviour and the desired qualities allocated with it is the actual reward and no other incentives are needed (Vallerand 2007). Extrinsic motivators can be helpful to raise the awareness of alternative behaviour patterns and invite individuals to test a different routine, but if the intrinsic value of the alternative does not gain awareness during this test, the former behaviour will return as soon as the incentives stop or the excitement of the new wears off (Millonig et al., 2016).

In the example provided in Table 2 the six different types could be motivated by specifically emphasising the qualities fitting to the respective motives for walking e.g. in campaigns or information sources. For the hedonistic type, walking has to be promoted as an opportunity to meet others and experience the environment. The responsible 
Table 2: Key characteristics and motives of pedestrians (based on Millonig, 2014; Markvica et al., 2020).

\begin{tabular}{|c|c|c|c|c|c|c|}
\hline Type & hedonistic & responsible & efficient & discerning & reserved & utilitarian \\
\hline Motion type & $\begin{array}{l}\text { - drifting } \\
\text { - flexible } \\
\text { - pauses }\end{array}$ & $\begin{array}{l}\text { - long trips } \\
\text { pauses }\end{array}$ & $\begin{array}{l}\text { - fast } \\
\text { - short trips }\end{array}$ & $\begin{array}{l}\text { selects pleas- } \\
\text { ant routes }\end{array}$ & $\begin{array}{l}\text { - few trips } \\
\text { - detours to } \\
\text { avoid sites }\end{array}$ & $\begin{array}{l}\text { - only neces- } \\
\text { sary trips } \\
\text { - } \text { short trips }\end{array}$ \\
\hline Motives & $\begin{array}{l}\text { - fun } \\
\text { - meeting others } \\
\text { - excitement }\end{array}$ & $\begin{array}{l}\text { - } \text { sustainability } \\
\text { - rationality } \\
\text { - } \text { health }\end{array}$ & $\begin{array}{l}\text { - rationality } \\
\text { - time } \\
\text { - comfort }\end{array}$ & $\begin{array}{l}\text { - enjoyment } \\
\text { - calm } \\
\text { - health }\end{array}$ & $\begin{array}{l}\text { · safety } \\
\text { · calm }\end{array}$ & $\begin{array}{l}\cdot \text { comfort } \\
\text { - costs }\end{array}$ \\
\hline Willingness to walk & · high & · high & - low & - medium & - low & - low \\
\hline
\end{tabular}

type usually does not need arguments, as they already strive to walk as much as possible for sustainability reasons. The efficient type often prefers faster modes of transport but can be convinced to walk more in situations where a footpath can save time and effort, a strategy which is for example followed by providing "metro walking maps" showing walking times between stations of the same or different lines (e.g. London ${ }^{1}$, Vienna ${ }^{2,3}$ ). The discerning type expects a certain quality and can be motivated if provided with a sense of exclusivity. For the reserved type, it is often less about making walking more attractive than removing emotional barriers, as they would walk more if the conditions would ease their concerns. Finally, the utilitarian type is generally difficult to convince to change their routine, hence walking as a mode of transport might only appear acceptable in certain circumstances when the costs and efforts of using other modes of transport are perceived as considerably higher than a trip on foot. In addition to type-specific arguments for walking as exemplified here, Markvica et al. (2020) also describe preferred communication channels (e.g. digital services, peer groups, role models, printed material) for each type to support the development of customised walking promotion strategies.

\section{Taking the next steps on the way to increase walking}

Many interventions aimed at increasing the share of walking focus on the "access" perspective and strive for developing attractive and walkable environments. Although this is certainly a precondition for inviting more people to walk at least a part of their daily trips, the simple barrier analysis based on three required components for behaviour change shows that well designed environments are essential but not necessarily sufficient to tackle the full potential of walkable trips.

While the amount of literature on walkability and respective urban design is vast, there is a scarcity of studies systematically exploring the "ability" component from a competence viewpoint (Millonig and Schechtner, 2007). Moreover, perceived low self-efficacy or past experiences with personal mistakes (e.g. getting lost) are closely intertwined with emotional barriers such as the fear of exposing oneself as incompetent or having to bear the consequences of one's own mistakes. Hence, more research is needed into how the design of environments can be made more "self-explaining" to support orientation and safe navigating, and how orientation aids can be designed to be as intuitive as possible (Graser 2017). On the other hand, research is also needed into the ways of raising the self-efficacy of social groups experiencing such barriers (Wunsch et al., 2015).

Finally, it is necessary to increase the number of studies into strategies helping to overcome emotional obstacles. Typologies and segmentation studies offer a useful basis for addressing those target groups that show little interest in walking in general. Understanding their core values can provide arguments to specifically anchor the benefits of walking in their respective value systems (Lindenberg and Steg, 2007). At the same time, the understanding of core values also provides deeper insights into the weight of different perceived barriers and the types of measures to prioritise in addressing the most significant barriers. In this way, the assessment framework described in this contribution can provide a useful tool to efficiently detect group-specific barriers, identify appropriate countermeasures and prioritise specific elements when dealing with limited resources to improve the physical and mental conditions for walking. In any case, the framework helps to take an integrated perspective and to become aware of the whole range of potential barriers and opportunities.

These objectives, however, require a radical change of perspective in transport planning and urban development away from a focus on infrastructure and mobility services towards a human-centred approach that addresses groupspecific barriers and uses appropriate indicators. In the context of an international project focusing on the assessment of socio-economic effects of automated transport, Zach, Millonig and Rudloff (2020), together with representatives of the Vienna Municipality and accompanied by a City Dialogue process involving stakeholders from different cities, developed a new set of indicators that focuses on the human perspective (see Table 3).

In this new perspective, it is striking that traditional transport-related indicators such as road capacities, passenger kilometres or number of vehicles registered are no longer the centre of attention; much greater importance is attached to behaviour-related indicators. The cities involved have also recognised that there is urgent need to develop methods and standards for measuring behaviour (change) related indicators. Approaches such as the one presented in this paper can also help to spark discussions about the relevance of currently established indicators, providing new opportunities to identify effective measures to increase active travel. 
Table 3: Urban development goal areas and indicators, including assessment of measurability (Zach, Millonig and Rudloff, 2020 p36).

\begin{tabular}{|c|c|c|c|}
\hline Dimension & Goal & Indicator & Measurability \\
\hline \multirow[t]{5}{*}{ Safety } & \multirow{2}{*}{$\begin{array}{l}\text { Protection of } \\
\text { Human Life }\end{array}$} & Number of injured per million inhabitants (per year) & +++ (already measured) \\
\hline & & Number of fatalities per million inhabitants (per year) & +++ (already measured) \\
\hline & Perceived Safety & Standardized survey: subjective rating of (overall) safety & ++ (already measured) \\
\hline & \multirow[t]{2}{*}{ Cyber Security } & Number of successful attacks per million trips completed & ? (measurability unclear) \\
\hline & & Number of vulnerabilities found (fixed?) (per year) & ? (measurability unclear) \\
\hline \multirow[t]{10}{*}{ Society } & \multirow[t]{2}{*}{ Reachability } & Average travel time per day (dispersion; goal: equal distribution) & + \\
\hline & & Number of opportunities per 30 minutes per mode of transport & ? (precise definition required) \\
\hline & \multirow[t]{2}{*}{ Use of publicspace } & Lane space per person & + \\
\hline & & Pedestrian/cycling space per person & + \\
\hline & \multirow[t]{4}{*}{ Inclusion } & $\begin{array}{l}\text { Distance to nearest publicly accessible transport stop (including } \\
\text { MaaS [Mobility as a Service]) }\end{array}$ & + \\
\hline & & $\begin{array}{l}\text { Affordability/discounts: to which degree are transport services } \\
\text { used by low-income groups }\end{array}$ & + \\
\hline & & $\begin{array}{l}\text { Barrier free accessibility: to which degree are transport services } \\
\text { used by socially disadvantaged and vulnerable groups, includ- } \\
\text { ing people with disabilities }\end{array}$ & + \\
\hline & & Quality of access restrictions/scoring & + (qualitative ind.) \\
\hline & \multirow[t]{2}{*}{ Satisfaction } & $\begin{array}{l}\text { Satisfaction with active transport infrastructure in neighbour- } \\
\text { hood (walking and/or cycling) }\end{array}$ & + \\
\hline & & Satisfaction public transport in neighbourhood & + \\
\hline \multirow[t]{6}{*}{ Environment } & Low noise levels & $\begin{array}{l}\text { Standardized survey: subjective rating of main sources of } \\
\text { disturbing noise }\end{array}$ & + \\
\hline & Clean air & $\begin{array}{l}\text { Emissions directly measurable: SO2, PM2,5, PM10, NO2, NO, } \\
\mathrm{NOx}, \mathrm{CO}, \mathrm{O} 3\end{array}$ & +++ \\
\hline & \multirow[t]{2}{*}{$\begin{array}{l}\text { Efficient settle- } \\
\text { ment structures }\end{array}$} & $\begin{array}{l}\text { Building volume per square kilometre } \\
\text { (total and per built-up area) }\end{array}$ & + \\
\hline & & Population density (Eurostat) & +++ \\
\hline & \multirow{2}{*}{$\begin{array}{l}\text { Sustainable } \\
\text { behaviour }\end{array}$} & Rate of energy consumption per person (total) & +++ \\
\hline & & Rate of energy consumption per person (transport related) & + \\
\hline \multirow[t]{2}{*}{ Economy } & Prosperity & Taxable income in relation to purchasing power & +++ \\
\hline & Fair distribution & GINI index & +++ \\
\hline
\end{tabular}

\section{Notes}

${ }^{1}$ https://content.tfl.gov.uk/walking-tube-map.pdf.

2 https://www.wienzufuss.at/wp-content/uploads/sites/3/2016/06/Plan-F_A4_2.pdf.

${ }^{3}$ https://www.wienzufuss.at/wp-content/uploads/sites/3/2016/11/Querverbindungen_A4.pdf.

\section{Acknowledgements}

The author is especially grateful to Karin Markvica (AIT) for her contribution in the description of type-specific characteristics in the pro:motion project. Special thanks also go to Matthias Wunsch for his efforts in the development of the theoretical basis for identifying strategies to increase self-efficacy in the context of active mobility and to Martin Zach (AIT), Christian Rudloff (AIT) and Helmut Augustin (City of Vienna) for their commitment to the development of a human-centred indicator set for urban governance.

\section{Funding Information}

The work presented in this paper is partly based on projects which received funding by Austrian authorities: pro:motion (FFG, grant no. 844066), and UCPNavi (FWF), and the H2020 project LEVITATE funded by the European Commission (grant no. 824361). 


\section{Competing Interests}

The author has no competing interests to declare.

\section{References}

Graser, A. 2017. Towards landmark-based instructions for pedestrian navigation systems using OpenStreetMap, Proceedings of the AGILE 2017 Conference on Geographic Information Science, Wageningen, The Netherlands, 9-12 May 2017.

Haustein, S and Hunecke, M. 2013. Identifying target groups for environmentally sustainable transport: Assessment of different segmentation approaches. In: Current Opinion in Environmental Sustainability, 5(2): S. 197-204. DOI: https://doi.org/10.1016/j.cosust.2013.04.009.

Johansson, M, Sternudd, C and Kärrholm, M. 2016. Perceived urban design qualities and affective experiences of walking. Journal of Urban Design, 21(2): 256-275. DOI: https://doi.org/10.1080/13574809.2015.1133225

Kelly, P, Murphy, M and Mutrie, N. 2017. The health benefits of walking. In: Mulley, C., Gebel, K. and Ding, D. (eds.) Walking, 9: 61-79. Emerald Publishing. DOI: https://doi.org/10.1108/S2044-994120170000009004

Krizek, KJ and Waddell, P. 2002. Analysis of lifestyle choices: Neighborhood type, travel patterns, and activity participation. Transportation Research Record: Journal of the Transportation Research Board, 1807(1): 119-128. DOI: https://doi.org/10.3141/1807-15

Lindenberg, S and Steg, L. 2007. Normative, gain and hedonic goal frames guiding environmental behavior. Journal of Social Issues, 63(1): 117-137. DOI: https://doi.org/10.1111/j.1540-4560.2007.00499.x

Markvica, K, et al. 2020. Promoting active mobility behavior by addressing information target groups: the case of Austria. Journal of Transport Geography, 83(C). DOI: https://doi.org/10.1016/j.jtrangeo.2020.102664

Millonig, A. 2014. My way - Towards a typology of pedestrian apatio-temporal behaviour in shopping environments. Dissertation. Department of Geodesy and Geoinformation, Vienna University of Technology.

Millonig, A. 2019. Connected and automated vehicles: Chances for elderly travellers. Gerontology, 65(5): 571-578. DOI: https://doi.org/10.1159/000498908

Millonig, A, et al. 2016. Gamification and social dynamics behind corporate cycling campaigns. Transportation Research Procedia, 19: 33-39. DOI: https://doi.org/10.1016/j.trpro.2016.12.065

Millonig, A and Schechtner, K. 2007. Decision loads and route qualities for pedestrians - key requirements for the design of pedestrian navigation services. In: Waldau, N. et al, (eds.) Pedestrian and evacuation dynamics 2005, Berlin, Heidelberg: Springer, 109-118. DOI: https://doi.org/10.1007/978-3-540-47064-9_10

Prillwitz, J and Barr, S. 2011. Moving towards sustainability? Mobility styles, attitudes and individual travel behaviour. Journal of Transport Geography, 19(6): 1590-1600. DOI: https://doi.org/10.1016/j.jtrangeo.2011.06.011

Reckwitz, A. 2002. Toward a theory of social practices. European Journal of Social Theory, 5(2), 243-263. DOI: https:// doi.org/10.1177/13684310222225432

Robertson, R, et al. 2012. Walking for depression or depressive symptoms: A systematic review and meta-analysis. Mental Health and Physical Activity, 5(1): 66-75. DOI: https://doi.org/10.1016/j.mhpa.2012.03.002

Shove, E, Pantzar, M and Watson, M. 2012. The dynamics of social practice: Everyday life and how it changes. London: SAGE Publications. DOI: https://doi.org/10.4135/9781446250655

Tomschy R, et al. 2016. Österreich unterwegs 2013/2014. Ergebnisbericht zur österreichweiten Mobilitätserhebung "Österreich unterwegs 2013/2014": Österreich unterwegs 2013/2014. Ergebnisbericht zur österreichweiten Mobilitätserhebung "Österreich unterwegs 2013/2014". Vienna, Austria.

Vallerand, RJ. 2007. Intrinsic and extrinsic motivation in sport and physical activity: A review and a look at the future. In: Tenenbaum, G and Eklund, RC (eds.) Handbook of sport psychology, 59-83. John Wiley and Sons, Inc. DOI: https:// doi.org/10.1002/9781118270011.ch3

WHO. Health Economic Assessment Tool (HEAT) for walking and for cycling: Methods and user guide on physical activity, air pollution, injuries and carbon impact assessments. Available from https://www.euro.who.int/_data/assets/ pdf_file/0010/352963/Heat.pdf [Accessed 14 March 2021].

Wunsch, M, et al. 2015. What makes you bike? Exploring persuasive strategies to encourage low-energy mobility. In: MacTavish, T and Basapur, S (eds.) Persuasive Technology, 9072: 53-64. Springer International Publishing. DOI: https://doi.org/10.1007/978-3-319-20306-5_5

Zach, M, Millonig, A and Rudloff, C. 2020. Definition of quantified policy goals: Deliverable D4.1 of the H2020 project LEVITATE. Available from https://levitate-project.eu/wp-content/uploads/2020/08/D4.1-Definition-of-QuantifiedPolicy-Goals.pdf [Accessed 8 April 2021]. 
How to cite this article: Millonig, A. 2021. What Drives Us to Walk: Understanding Components and Processes of Behaviour Change Towards Active Mobility. Active Travel Studies: An Interdisciplinary Journal, 1(1): 4, 1-6. DOI: https://doi.org/10.16997/ats.1075

Submitted: 06 May 2021

Accepted: 19 May 2021

Published: 11 August 2021

Copyright: ( $) 2021$ The Author(s). This is an open-access article distributed under the terms of the Creative Commons Attribution 4.0 International License (CC-BY 4.0), which permits unrestricted use, distribution, and reproduction in any medium, provided the original author and source are credited. See http://creativecommons.org/licenses/by/4.0/. 